\title{
Development of a cell-based treatment for long-term neurotrophin expression and spiral ganglion neuron survival
}

\author{
Mark P. Zanin ${ }^{\mathrm{a}, 1}$, Mats Hellström ${ }^{\mathrm{c}, 2}$, Robert K. Shepherd ${ }^{\mathrm{a}, \mathrm{b}}$, Alan R. Harvey ${ }^{\mathrm{c}}$ \\ and Lisa N. Gillespie ${ }^{\mathrm{a}, \mathrm{b}^{*}}$
}

${ }^{a}$ Bionics Institute, Melbourne, Australia

${ }^{b}$ Department of Medical Bionics, University of Melbourne, Australia

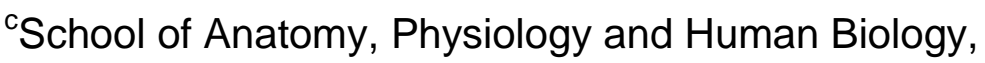
The University of Western Australia, Australia

${ }^{*}$ Correspondence should be addressed to:

Dr Lisa N. Gillespie

Bionics Institute

384 Albert Street,

East Melbourne, VIC 3002 Australia

Email: Igillespie@bionicsinstitute.org

Phone: +61 39667 7580; Fax: +61 396677518

\footnotetext{
${ }^{1}$ Current address: Department of Infectious Diseases, St Jude Children's Research Hospital, Memphis, TN, USA; ${ }^{2}$ Current address: Laboratory for Transplantation and Regenerative Medicine, Dept. of Obstetrics and Gynecology, Sahlgrenska Academy, University of Gothenburg, Sweden
} 


\section{Abbreviations}

BDNF: brain-derived neurotrophic factor

D10: DMEM plus FCS, L-glutamine, penicillin and streptomycin

D10M: D10 medium plus bovine pituitary extract and forskolin

DMEM: Dulbecco's Modified Eagle's Medium

EGFP: enhanced green fluorescent protein

ELISA: enzyme linked immunosorbant assay

FCS: fetal calf serum

IQR: inter-quartile range

NT3: neurotrophin-3

PBS: phosphate buffered saline

pEGFP: plasmid encoding EGFP

pBDNF-E: plasmid encoding EGFP-tagged BDNF

pNT3-E: plasmid encoding EGFP-tagged NT3

pLV-EGFP: lentiviral plasmid encoding EGFP

pLV-BDNF: lentiviral plasmid encoding BDNF

pLV-NT3: lentiviral plasmid encoding NT3

SGNs: spiral ganglion neurons

SNHL: sensorineural hearing loss

TBS-T: Tris-buffered saline with Tween 20 


\section{Abstract}

Spiral ganglion neurons (SGNs), the target cells of the cochlear implant, undergo gradual degeneration following loss of the sensory epithelium in deafness. The preservation of a viable population of SGNs in deafness can be achieved in animal models with exogenous application of neurotrophins such as brain-derived neurotrophic factor (BDNF) and neurotrophin-3. For translation into clinical application, a suitable delivery strategy that provides ongoing neurotrophic support and promotes long-term SGN survival is required. Cell-based neurotrophin treatment has the potential to meet the specific requirements for clinical application, and we have previously reported that Schwann cells genetically modified to express BDNF can support SGN survival in deafness for four weeks. This study aimed to investigate various parameters important for the development of a long-term cell-based neurotrophin treatment to support SGN survival. Specifically, we investigated different (i) cell types, (ii) gene transfer methods and (iii) neurotrophins, in order to determine which variables may provide long-term neurotrophin expression and which, therefore, may be the most effective for supporting long-term SGN survival in vivo. We found that fibroblasts that were nucleofected to express BDNF provided the most sustained neurotrophin expression, with ongoing BDNF expression for at least 30 weeks. In addition, the secreted neurotrophin was biologically active and elicited survival effects on SGNs in vitro. Nucleofected fibroblasts may therefore represent a method for safe, long-term delivery of neurotrophins to the deafened cochlea to support SGN survival in deafness.

Keywords: neurotrophin; nucleofection; lipofection; lentivirus; spiral ganglion neuron; sensorineural hearing loss 


\section{Introduction}

Sensorineural hearing loss (SNHL), the most common form of deafness, is typically caused by the loss of cochlear hair cells. The only therapeutic treatment for patients with severe-profound SNHL is a cochlear implant - a neural prosthesis that electrically stimulates the residual spiral ganglion neuron (SGN) population to provide the rate and pitch cues necessary for speech perception. In the normal cochlea, the hair cells and supporting cells of the organ of Corti support the survival of SGNs through endogenous neurotrophin secretion (Fritzsch et al., 2004; Stankovic et al., 2004; Green et al., 2012; Zilberstein et al., 2012), and therefore damage to the organ of Corti and loss of this neurotrophin support, as occurs in SNHL, leads to the loss of SGNs. Since SGNs are the target cells for the cochlear implant, the loss of a significant population of SGNs may compromise the function of the device (Pfingst and Sutton, 1983; Shepherd and Javel, 1997; Hardie and Shepherd, 1999). Furthermore, future developments in device and software design may also benefit from an enhanced SGN population (Wise and Gillespie, 2012).

Exogenous delivery of neurotrophins such as brain-derived neurotrophic factor (BDNF) and neurotrophin-3 (NT3) can support SGN survival in models of deafness (Ernfors et al., 1996; Miller et al., 1997; Gillespie et al., 2003; Gillespie et al., 2004; Yamagata et al., 2004; Richardson et al., 2005; Shepherd et al., 2005). However, the cessation of exogenous neurotrophin treatment can result in a loss of these survival effects (Gillespie et al., 2003; Shepherd et al., 2005). While others have reported continued auditory neuron survival for two weeks post-treatment (Agterberg et al., 2009), long-term outcomes remain unknown. Chronic electrical stimulation via a cochlear implant extends neurotrophin-based survival effects past the end of 
neurotrophin treatment; however, to maximise SGN rescue, long-term neurotrophin delivery is desirable (Shepherd et al., 2005; Shepherd et al., 2008).

Current methods of neurotrophin delivery into the cochlea, such as osmotic pumps, are not considered suitable for clinical application (Pettingill et al., 2007). Alternative pump-based delivery systems must be re-filled at regular intervals, necessitating multiple surgical procedures. This poses a small but significant risk of infection, which could result in labyrinthitis and meningitis (Wei et al., 2008). Furthermore, neurotrophins have a short half-life (Lindholm et al., 1988; Matsuoka et al., 1991; Poduslo and Curran, 1996; Kishino et al., 2001), meaning that the use of long-term pump delivery systems with high volume capacities may be complicated by the unknown bioactivity of neurotrophins maintained at body temperature for long periods.

Cell-based therapies, in which cells secreting a therapeutic substance are implanted into a patient, are an alternative mechanism for continuous delivery of neurotrophins into the cochlea (for review see Zanin et al., 2012). Cell-based therapies may utilise cells which naturally secrete therapeutic agents (Wise et al., 2011), or may be combined with gene transfer techniques to genetically modify cells to secrete the desired therapeutic agent(s) (Pettingill et al., 2008; Pettingill et al., 2011). Cell-based therapies provide an avenue for delivering neurotrophins at physiological levels and in a consistent manner, and also overcome issues of infection (Shepherd, 2011) and longevity of survival effects (Gillespie et al., 2003; Shepherd et al., 2005) associated with other experimental delivery methods. In addition, cell-based therapies have the potential for long-term neurotrophin expression (Winn et al., 1996). For these reasons, cell-based therapies are considered clinically viable, and have already been implemented for therapeutic drug 
delivery in clinical trials for various neurodegenerative conditions (for review see Zanin et al., 2012).

Previously, we successfully genetically modified Schwann cells using lipofection to express BDNF or NT3 and demonstrated that these cells could support SGN survival in vitro (Pettingill et al., 2008). Furthermore, we reported that the implantation of encapsulated, BDNF-secreting Schwann cells into the deaf guinea pig cochlea successfully supported SGN survival over two and four week implantation periods (Pettingill et al., 2011). Whilst promising, longer-term studies, using cells with a greater duration of neurotrophin secretion, are required in order to best assess the potential of this therapy for ongoing SGN survival (Pettingill et al., 2011).

There are numerous experimental parameters that may play an important role in achieving longer-term neurotrophin expression from a cell-based treatment. In the current study, we investigated different (i) cell types, (ii) gene transfer techniques and (iii) neurotrophins, with the aim of developing a population of cells that reliably secreted neurotrophin for periods of time significantly greater than four weeks.

\section{Experimental Procedures}

We utilised an array of test conditions in order to develop cells with long-term neurotrophin expression. Specifically, Schwann cells and fibroblasts were genetically modified using lipofection or nucleofection to express BDNF or NT3. Schwann cells were also genetically modified using lentiviral vectors to express these neurotrophins. The resultant neurotrophin-expressing cells were compared in terms of transfection efficiency, and duration and quantity of neurotrophin expression. The bioactivity of 
the secreted neurotrophins was assessed by quantifying survival effects on SGNs in vitro.

All experiments involving animals were carried out with approval from the Animal Research and Ethics Committee of the Royal Victorian Eye and Ear Hospital, Australia (Project \# 09/179AB), in accordance with The Australian Code of Practice for the Care and Use of Animals for Scientific Purposes (1997), and the National Institute of Health Guide for the Care and Use of Laboratory Animals (1996). All efforts were made to minimise pain and the number of animals used.

\section{Preparation of primary Schwann cell and fibroblast cultures}

Schwann cells and fibroblasts were isolated from rat sciatic nerve explants using established protocols (Morrissey et al., 1991; Plant et al., 2002; Godinho et al., 2013). Briefly, 8-10 week old rats were killed using sodium pentobarbitone (150 $\mathrm{mg} / \mathrm{kg}$ intraperitoneally) and the sciatic nerves removed. The perineurium was dissected from the nerve and the nerve was cut into segments of approximately 1 $\mathrm{mm}$ length and placed into $60 \mathrm{~mm}$ dishes containing $1 \mathrm{~mL}$ D10 medium [Dulbecco's Modified Eagle's Medium (DMEM; Invitrogen) with 10\% fetal calf serum (FCS; Invitrogen), $2 \mathrm{mM} \mathrm{L-glutamine} \mathrm{(Invitrogen),} 100$ units/mL penicillin (Invitrogen) and $100 \mathrm{mg} / \mathrm{mL}$ streptomycin (Invitrogen)], and incubated at $37^{\circ} \mathrm{C}$ in $5 \% \mathrm{CO}_{2}$. Fibroblasts begin to migrate from the nerve explants first (Plant et al., 2002; Godinho et al., 2013), and can be collected by repeated re-plating of the explants into new tissue culture plates to avoid Schwann cell contamination. Specifically, one week after the initial plating, the explants were transferred to a new dish containing D10, and the remaining adherent cells were washed with phosphate buffered saline (PBS; pH 7.2), the medium was replenished, and the fibroblasts were cultured at $37^{\circ} \mathrm{C}$ in $5 \% \mathrm{CO}_{2}$. 
This procedure was repeated on a weekly basis for 3-4 weeks, until Schwann cells were identified growing out from the explants, as based upon their spindle-like morphology. All tissue culture dishes containing only fibroblasts were then pooled and grown in D10 in 75mm tissue culture flasks.

The Schwann cell-containing explants were then collected and dissociated using a solution of dispase $(1.25 \mathrm{U} / \mathrm{mL})$ and collagenase $(0.05 \%)$, spun, resuspended in D10 containing the mitogens bovine pituitary extract $(20 \mu \mathrm{g} / \mathrm{mL})$ and forskolin (2 $\mu \mathrm{M} / \mathrm{mL})$ [D10M], and grown in tissue culture flasks coated with poly-Llysine $(100 \mu \mathrm{g} / \mathrm{mL}$; Sigma).

Immunostaining of Schwann cell and fibroblast cultures

Confluent cells grown on 2-well chamber slides were fixed with ice-cold methanol (30 minutes), rinsed with PBS and immunostained with antibodies to S100 and Thy1.1 to label Schwann cells and fibroblasts, respectively. These are the two cell types dominating the cultures derived from the peripheral nerve explants and therefore can be used to confirm the purity of the cultures.

The cultures were incubated with 2\% FCS in PBS (1 hour) followed by addition of primary and secondary antibodies in sequence. Specifically, cultures were incubated with mouse anti-Thy1.1 (MAB1406, Millipore; 1:150) and rabbit anti-S100 (Z0311, DAKO; 1:500) for 1 hour at room temperature, rinsed with 2\% FCS in PBS (3x 5 minutes) and incubated with goat anti-mouse 488 (for Thy1.1) or goat antirabbit 594 (for S100) secondary antibodies (Alexa Fluor; Molecular Probes) at 1:500 for 1 hour at room temperature. Following staining, cultures were rinsed with PBS ( $3 \times 5$ minutes), the chambers were removed and slides were rinsed briefly in distilled water and cover-slipped with Vectashield (Vector Labs). 


\section{Fibroblast and Schwann cell transfection}

Neurotrophin expression plasmids

Expression plasmids encoding the reporter gene enhanced green fluorescent protein (pEGFP), C-terminal EGFP-tagged BDNF (pBDNF-E) or C-terminal EGFPtagged NT3 (pNT3-E) were kindly provided by Dr Volkmar Lessmann (Johannes Gutenberg Universität, Mainz, Germany), and had been constructed by insertion of the complete sequence of prepro rat BDNF or prepro human NT3 cDNA into the cytomegalovirus-promoter driven pEGFP-N1 expression vector (Clontech, Cambridge, UK) as previously described (Haubensak et al., 1998; Hartmann et al., 2001; Brigadski et al., 2005). The original Clontech pEGFP-N1 vector was used as the pEGFP control.

Lentivirus plasmids encoding EGFP (pLV-EGFP), BDNF (pLV-BDNF) and NT3 (pLV-NT3) were constructed from relevant cDNA cloned into the pRRLsinPPThCMVMCSpre lentiviral transfer vector backbone (Hu et al., 2005; Hu et al., 2007; Godinho et al., 2013). Lentiviral stocks were produced by co-transfection of these plasmids and packaging and envelope plasmids into 293T cells. After 2 days, medium with viral particles was harvested, concentrated by ultracentrifugation, dissolved in PBS and stored at $-80^{\circ} \mathrm{C}$. Titers were expressed as transducing units (TU) per milliliter and concentrated stocks ranged in the order of $10^{8}$ to $10^{9} \mathrm{TU} / \mathrm{mL}$. Gene transfer techniques

Separate cultures of Schwann cells and fibroblasts were transfected with the pEGFP, pBDNF-E and pNT3-E plasmids using lipofection or nucleofection. Additional populations of Schwann cells were lentivirally infected with the pLV-EGFP, pLV- 
BDNF and pLV-NT3 plasmids. A total of 15 different cell populations expressing BDNF, NT3 or EGFP were prepared.

\section{Lipofection}

Cells were transfected using Lipofectamine LTX (Invitrogen) as per manufacturer's instructions. Briefly, cells at approximately $80 \%$ confluency were rinsed with PBS and fresh medium without antibiotics was added. DNA:lipid complexes were prepared at a 1:3 ratio of DNA $(\mu \mathrm{g})$ to lipofectamine $(\mu \mathrm{L})$ in OptiMEM reduced serum medium (Invitrogen). Lipofectamine PLUS reagent was also added at a ratio of $1 \mu \mathrm{L}$ per $\mu \mathrm{g}$ of DNA. Complexes were allowed to form by incubation at room temperature for 30 minutes and were then added to the cells and incubated at $37^{\circ} \mathrm{C}, 5 \% \mathrm{CO}_{2}$ for 5 hours. Fresh medium without antibiotics was applied to the cultures, and successful transfection was confirmed under direct fluorescence microscopy. Selection of transformants was commenced with the addition of geneticin (G418 sulphate, $400 \mu \mathrm{g} / \mathrm{mL}$; Invitrogen), and following two weeks of selective pressure the cells were maintained in culture under $300 \mu \mathrm{g} / \mathrm{mL}$ geneticin. Once confluent the cells were subcultured weekly.

\section{$\underline{\text { Nucleofection }}$}

Fibroblasts and Schwann cells were nucleofected using a Nucleofector II with a Basic Nucleofector Kit for primary mammalian fibroblasts or endothelial cells, respectively (Lonza). Cells at approximately $80 \%$ confluency were rinsed with PBS, trypsinised and pelleted, and $1 \times 10^{6}$ cells were then used per reaction, using program T-16 as per manufacturer's instructions. Selection was carried out as described above and cells were subcultured weekly after reaching confluence. 


\section{Lentiviral infection}

Schwann cells at approximately $80 \%$ confluency were rinsed with PBS and separate cultures were incubated with the replication-deficient lentiviral vectors, diluted in D10M so that the multiplicity of infection $=1: 50$, for 24 hours. The cultures were then washed, medium replenished, and cells were maintained in D10M cell culture medium. Cells were subcultured weekly.

\section{Neurotrophin quantification}

Conditioned medium was collected from transfected cells weekly and neurotrophin secretion was measured by enzyme-linked immunosorbant assay (ELISA) using eMax Immunoassays for BDNF and NT3 (Promega). ELISA plates (BD Falcon) were incubated overnight with the respective coating antibody diluted in block and sample buffer at $4{ }^{\circ} \mathrm{C}$ and then washed once with Tris buffered saline with Tween 20 wash buffer (TBS-T; 20mM Tris-HCl (pH 7.6), $150 \mathrm{mM} \mathrm{NaCl,} \mathrm{0.05 \%} \mathrm{(v/v)}$ Tween 20). Plates were then blocked by incubation with block and sample buffer for 1 hour at room temperature, washed once with TBS-T wash buffer, and samples and standards were added. Neurotrophin standards were diluted in block and sample buffer as per manufacturer's instructions, whilst conditioned medium was used at stock concentration. Plates were incubated for 6 hours (NT3 ELISAs) or 2 hours (BDNF ELISAs) at room temperature with shaking then washed 5 times with TBS-T wash buffer. Primary antibodies were added to the plates and incubated overnight at $4^{\circ} \mathrm{C}$ with shaking (NT3 ELISAs) or for 2 hours at room temperature with shaking (BDNF ELISAs) and subsequently washed 5 times with TBS-T wash buffer. Horseradish peroxidase-conjugated antibodies were added to the plates and incubated for 2.5 hours (NT3 ELISAs) or 1 hour (BDNF ELISAs) at room temperature with shaking. Plates were then washed 5 times with TBS-T wash buffer and TMB 
was added to all wells and incubated at room temperature with shaking for 15 mins (NT3 ELISAs) or 10 mins (BDNF ELISAs). Reactions were then stopped by addition of $1 \mathrm{~N} \mathrm{HCl}$, and absorbance was measured at $450 \mathrm{~nm}$. Samples were run in triplicate in at least 2 separate ELISAs $(n \geq 6)$.

\section{Spiral ganglion neuron cultures}

\section{Preparation of SGN cultures}

SGN cultures were prepared from postnatal day 5-6 albino Wistar rat pups, as previously described (Gillespie et al., 2001; Pettingill et al., 2008). Briefly, rat pups were rendered unconscious on ice and rapidly decapitated. The bulla was dissected from each temporal bone, the bony otic capsule removed and the cochlea isolated. The auditory nerve was severed at the internal auditory meatus and the organ of Corti was removed. The central core of all cochleae were pooled and digested in calcium-magnesium-free Hanks' Buffered Salt Solution (Invitrogen) containing $0.025 \%$ trypsin (Trace) and $0.001 \%$ DNase (Roche, Castle Hill, NSW, Australia) for $20 \mathrm{~min}$ at $37^{\circ} \mathrm{C}$. FCS was used to inhibit trypsin prior to centrifugation and resuspension in HEPES buffered Eagle's medium (Invitrogen) with $0.001 \%$ DNase. Tissue was then mechanically digested through a series of needles, spun and resuspended in DMEM containing $4.5 \mathrm{~g} / \mathrm{L}$ glucose (Invitrogen) and 1x N2 supplement (Gibco).

Neurotrophin bioassays

SGNs were plated onto poly-ornithine ( $500 \mu \mathrm{g} / \mathrm{mL}$; Sigma) and laminin (10 $\mu \mathrm{g} / \mathrm{mL}$; Invitrogen) coated dishes as previously described (Gillespie et al., 2001; Pettingill et al., 2008). Transfected cells secreting EGFP, NT3 or BDNF at either 8 weeks or 16 weeks post transfection were seeded into cell culture inserts (Millipore), 
placed into the SGN culture dishes. Thus, the inserts kept the cells physically separated but allowed exchange of culture medium. SGNs and transfected cells were plated at a ratio of $\sim 1: 3$ per well, respectively. After 3 days in culture, cells were fixed in ice-cold methanol for 30 minutes followed by three washes in PBS.

\section{Immunostaining}

Immunostaining was performed using the avidin-biotin complex method of a standard Vectastain kit (Vector), as per manufacturer's instructions. Cultures were blocked by incubation with 2\% FCS in PBS for 30 minutes and immunostained with rabbit anti-neurofilament $200 \mathrm{kDa}$ (AB1982, Chemicon; 1:400) in 2\% PBS for 30 minutes. This antibody is produced using the C-terminus of the rat neurofilament- $\mathrm{H}$ protein and recognizes both phosphorylated and unphosphorylated forms of the protein. Cultures were then washed with $2 \%$ FCS in PBS ( $3 \times 5$ minutes) followed by biotinylated anti-rabbit secondary antibody (1:200, 30 minutes); PBS ( $3 \times 5$ minutes); avidin-biotin complex (1:100, 30 minutes); PBS ( $3 \times 5$ minutes); diaminobenzidine chromogen substrate (Vector) until a colour change was observed (10-20 seconds) and distilled water ( $3 \times 5$ minutes). Immunostained cultures were stored in $2 \%$ sodium azide solution.

\section{Analysis and statistics}

Neurotrophin expression

Cell culture medium collected weekly was analysed for BDNF and NT3 content, with at least $n=3$ per transfected cell type at each time point, over at least two separate ELISAs (ie. $n \geq 6$ ). Comparisons in neurotrophin content were made between the conditioned medium and the respective EGFP control medium for each cell type at each time point using a $t$-test and SigmaPlot statistical and graphing 
software (Aspire Software International). A difference was considered to be statistically significant when $P<0.05$

\section{SGN survival}

A total of at least $n=37$ replicates per co-culture treatment condition were performed across seven independent experiments. Surviving neurons were identified by immunopositivity for neurofilament, and were only included in counts if they displayed a clear nucleus and projections at least three times the diameter of the neuronal soma, ensuring that only healthy neurons were counted (Gillespie et al., 2001). All surviving neurons in each well were counted.

In each experiment, SGNs in the control (EGFP) co-cultures were counted and the average SGN survival (per well) in these control cultures was standardized to $100 \%$. The number of surviving SGNs per well in each treatment condition - EGFP, BDNF and NT3 co-cultures - were then expressed as a percentage relative to the mean of the control. This was repeated for each experiment, and the data pooled for statistical analysis.. Statistical analyses were performed using SigmaPlot and significant differences were identified using a Kruskal-Wallis One Way Analysis of Variance on Ranks and Dunn's Method for an All Pairwise Multiple Comparison Procedure. A difference was considered to be statistically significant when $P<0.05$.

\section{Results}

In this study we compared various approaches for cell transfection with the aim of developing a protocol that would generate cells with long-term neurotrophin secretion at levels sufficient to support SGN survival in vitro. Specifically, we genetically modified Schwann cells and fibroblasts to express EGFP, BDNF or NT3 
using lipofection and nucleofection, and also genetically modified Schwann cells to express these genes using lentiviral vectors. We assessed the outcomes by quantifying the amount and duration of neurotrophin secretion for each population of cells.

\section{Purity of cell cultures}

The purity of each of the cultures was confirmed by immunohistochemistry using antibodies against Thy1.1 to stain for fibroblasts and S100 to stain for Schwann cells (Brockes et al., 1977; Haastert et al., 2007) (Figure 1). The purity of the fibroblast cultures was confirmed by positive immunostaining for Thy 1.1 and negative staining for S100. Conversely, the purity of the Schwann cell cultures was confirmed by positive immunostaining for $\mathrm{S} 100$ and negative staining for Thy1.1.

\section{Efficacy and success of gene transfer}

Lipofected and nucleofected Schwann cells and fibroblasts, and lentivirally infected Schwann cells, were all successfully genetically modified for EGFP as evidenced by the fluorescence of the transfected cells. Importantly, none of these EGFPexpressing cell populations secreted detectable amounts of BDNF or NT3. The success of the neurotrophin gene transfer varied for each method based upon the cell type (Table 1).

Schwann cells

Using lipofectamine, Schwann cells were successfully genetically modified with expression vectors that expressed EGFP, EGFP-tagged BDNF or EGFP-tagged NT3, as evidenced by fluorescence of the transfected cells. Based on the numbers of fluorescent to non-fluorescent cells, we attained a transfection efficiency of 
approximately $10 \%$ for each gene. Importantly, following selection with geneticin, we could not identify any non-fluorescing cells in our cultures. The lipofected Schwann cells initially secreted statistically significantly increased amounts of NT3 (66.03 \pm $2.17 \mathrm{pg} / \mathrm{mL}$, mean \pm SEM; $P<0.01$ ) as compared to the EGFP-Schwann cells; however, NT3 expression decreased over time and at ten weeks post-transfection no further NT3 could be detected in the conditioned medium (Figure 2). Lipofected BDNF-Schwann cells initially produced small but statistically significant amounts of BDNF as compared to the EGFP-Schwann cells $(8.2 \pm 0.5 \mathrm{pg} / \mathrm{mL} ; P<0.05)$; however, this expression ceased by six weeks post-transfection (Figure 2).

Schwann cells were also successfully genetically modified using lentivirus to express each of the genes. Similarly to the lipofected Schwann cells, both the lentiviral NT3-Schwann cells (76.5 $\pm 14.9 \mathrm{pg} \mathrm{NT3/mL)}$ and BDNF-Schwann cells $(62.6 \pm 11.1 \mathrm{pg} \mathrm{BDNF/mL})$ secreted significantly greater amounts of the respective neurotrophin in comparison to the control EGFP-cells $(P<0.01)$ in the early stages post-transfection; however, the duration of neurotrophin expression from these cells was only observed for 14 and nine weeks, respectively (Figure 3). We also observed an apparent 'cyclic' rate of neurotrophin expression by the lentiviral NT3-Schwann cells, with peaks and troughs in terms of the concentration of neurotrophin detected in the conditioned medium over time.

Interestingly, Schwann cells did not recover from the nucleofection procedure well, with cells transfected for both BDNF and NT3 genes dying soon after the procedure. 


\section{Fibroblasts}

Fibroblasts were successfully lipofected to express both BDNF and NT3, with a transfection efficiency of approximately $10 \%$, similar to that achieved using this technique in Schwann cells. The lipofected fibroblasts initially secreted the respective neurotrophin at statistically greater amounts than control EGFP-fibroblasts (Figure 4), with $146.7 \pm 28.0 \mathrm{pg} / \mathrm{mL}$ BDNF $(P<0.01)$ and $455.23 \pm 33.22 \mathrm{pg} / \mathrm{mL} \mathrm{NT3}(P<0.01)$ However, this expression decreased over time and had ceased by nine weeks posttransfection for the BDNF-fibroblasts and 11 weeks for the NT3-fibroblasts.

Fibroblasts were also successfully nucleofected to express both BDNF and NT3, with a transfection efficiency of approximately $80 \%$. The nucleofected NT3fibroblasts secreted up to $313.5 \pm 33 \mathrm{pg} \mathrm{NT} 3 / \mathrm{mL}$ in the early stages post-transfection, and exhibited cyclic neurotrophin expression with an average of $136.7 \pm 17.2 \mathrm{pg} / \mathrm{mL}$ $(P<0.01)$. These cells expressed the NT3 expression over a 16-week time-frame (Figure 5). In comparison, the nucleofected BDNF-fibroblasts secreted statistically greater amounts of neurotrophin $(P<0.01)$ over the longest time-course of all transfected cells, with ongoing neurotrophin expression for 30 weeks (Figure 6), at an average of $23.3 \pm 2.0 \mathrm{pg} \mathrm{BDNF/mL}$. These cells also exhibited cyclic neurotrophin expression, although despite this, the amount of BDNF expressed actually increased over time (Figure 6). Therefore, of the parameters tested, fibroblasts that were nucleofected to express BDNF provided the greatest duration and most stable neurotrophin expression.

\section{Nucleofected fibroblasts support spiral ganglion neuron survival in vitro}

In order to assess the bioactivity of the neurotrophin secreted from the transfected cells, neurotrophin-expressing cells were grown in co-culture with SGNs 
in an in vitro model of deafness. Since the nucleofected fibroblasts had the greatest duration of neurotrophin expression of the cell populations tested, these co-culture experiments were only performed with this transduced cell type.

SGNs were co-cultured with nucleofected fibroblasts for three days and the number of surviving SGNs was then quantified. To determine if time post-transfection affected the trophic action of the nucleofected fibroblasts, we used cells from two different time-points, 8 weeks post-transfection and 16 weeks post-transfection. However, we did not see any significant differences between these two time points (data not shown), and so these data were pooled. Both nucleofected NT3-fibroblasts (median $=133 \%$, inter-quartile range $(I Q R)=103-200 \%)$ and BDNF-fibroblasts (median=135.54\%, IQR=91.02-214.29\%) elicited significant survival effects $(P<$ 0.001) on SGNs in vitro over control EGFP-fibroblasts (median=98.63\%, IQR $=38.58$ 135.16\%; Figure 7). Therefore, the amount of neurotrophin secreted by the nucleofected fibroblasts was sufficient to elicit significant survival effects on SGNs in vitro. We also measured SGN soma size and axon length and found no statistically significant differences between neurotrophin treated and untreated SGNs (data not shown), indicating that co-culture did not have an effect on neuronal morphology.

\section{Discussion}

This study was undertaken to produce a population of primary cells that secrete neurotrophin for extended periods of time at concentrations that support SGN survival. We genetically modified Schwann cells and fibroblasts using lipofection and nucleofection, and also genetically modified Schwann cells using lentiviral vectors, to express two genes known to be important in the auditory system - BDNF and NT3. From the parameters tested we demonstrated that nucleofected BDNF-expressing 
fibroblasts provided the greatest duration of neurotrophin expression. The quantities of neurotrophins secreted by nucleofected fibroblasts were effective in supporting SGN survival in vitro. The application of nucleofected fibroblasts therefore provides a promising technique for SGN rescue in vivo.

\section{Nucleofection induces long-term neurotrophin secretion}

Nucleofected fibroblasts secreted BDNF for 30 weeks and NT3 for 16 weeks. In comparison, lipofected fibroblasts and Schwann cells secreted neurotrophin for 6-10 weeks. The superiority of nucleofection over lipofection in regards to longevity of neurotrophin secretion is likely due to the permeabilization of the nuclear membrane that occurs as part of the nucleofection process, thus permitting DNA delivery directly into the nucleus and making stable integration more likely. In comparison, lipofection relies on the endocytosis of lipid/DNA complexes by the cell and the DNA is subsequently localised to the cytoplasm, meaning it is more likely to be subjected to degradation (Hamm et al., 2002). In addition, the direct delivery of DNA into the nucleus allows for gene transcription independent of cell division, which is an important consideration when dealing with primary cells. Nucleofection was also more efficient than lipofection in terms of the proportion of cells transfected, which was also likely due to the delivery of DNA into the nucleus. By observing the ratio of fluorescent to non-fluorescent cells 24 hours post transfection, we estimated an $80 \%$ transfection efficiency by nucleofection compared to a $10 \%$ efficiency by lipofection. These values are similar to those reported in other studies that used these techniques in fibroblasts, which range from $43 \%$ to almost $100 \%$ for nucleofection and 3-8\% for lipofection (Badakov and Jazwinska, 2006; Nakayama et al., 2007; Skrzyszowska et al., 2008). 
Although viral infection also involves delivery of the inserted gene directly into the nucleus of the target cells, and therefore long-term gene expression may be expected, neurotrophin expression by lentivirally-infected Schwann cells in this study was only observed for 14 weeks. While this is of significantly shorter duration than that of the nucleofected fibroblasts, it is similar to that previously reported for lentivirally-infected Schwann cells, in which gene expression remained visible for 12 weeks (Hu et al., 2005). The variability in transfection efficiency and duration of gene expression across different gene transfer methods can also be influenced by, and indeed highly dependent upon, the cell type being transfected (Maurisse et al., 2010). Specifically, when comparing gene transfer success in Schwann cells in this study, lentiviral transduction was superior to nucleofection, since the latter technique unexpectedly resulted in irreparable damage to the cultured Schwann cells. In this study, we did not have a population of fibroblasts that were lentivirally transduced, and so direct comparisons between these two techniques in fibroblasts cannot be made. Previous studies have reported successful lentiviral transduction of fibroblasts to express BDNF (Warnecke et al., 2007; Warnecke et al., 2012), and more significantly, that these BDNF-expressing fibroblasts could support SGN survival both in vitro (Warnecke et al., 2007) and in vivo (Warnecke et al., 2012). While these studies did not specifically investigate the longevity of the neurotrophin expression from these cells, it is possible that fibroblasts lentivirally transduced to express BDNF could elicit similar long-term neurotrophin expression patterns as nucleofected fibroblasts. Nonetheless, given the positive long-term expression pattern from nucleofected fibroblasts in this study, nucleofection is an extremely promising technique for long-term cell-based neurotrophin expression that abrogates any concerns surrounding the use of viruses. 
While nucleofected fibroblasts exhibited longer neurotrophin expression than any of the other combinations of cell types and gene transfer methods tested, we also observed a difference in the longevity of expression between nucleofected BDNF-fibroblasts, which expressed BDNF for 30 weeks, and nucleofected NT3fibroblasts, which secreted NT3 for 16 weeks. Whilst the reasons for this discrepancy are unclear, there are several possibilities which could lie at the DNA or protein level. It is possible that the integration of the NT3 plasmid was not as stable as the BDNF plasmid, which may have led to the DNA being lost from the cell and thus NT3 expression to cease. In addition, the neurotrophin constructs used in this study encoded rat BDNF and human NT3; however, since the sequences of human and rat BDNF and NT3 are completely conserved, and the pro-forms of these neurotrophins are also highly conserved between human and rat (Maisonpierre et al., 1991), this is unlikely to account for the increased longevity of neurotrophin expression of BDNF over NT3. At the protein level, BDNF has been shown to display greater stability than NT3 (Timm et al., 1994), although this is unlikely to account for the increased longevity of expression observed as we measured neurotrophin levels from conditioned medium collected weekly. However, at lower concentrations, increased degradation of NT3 may compromise the sensitivity of the ELISA method used here, which requires the binding of two different antibodies against two different epitopes of the protein (Zhang et al., 2001). Therefore, NT3 secretion beyond 16 weeks post transfection may have been below the detection threshold of the ELISA method.

We also observed that for some of the transfected cells there was an apparent cyclic rate of neurotrophin expression, with peaks and troughs in terms of the concentration of neurotrophin detected in the conditioned media over time (Figures 3 , 5 and 6). While the precise mechanism or underlying cause of this differential rate of 
expression is unclear, it may be the result of autocrine feedback mechanisms occurring in response to the neurotrophins secreted by the cells themselves. Indeed, both BDNF and NT3 are known to influence cell survival, differentiation and proliferation, predominantly on neurons, but also on non-neuronal cells including fibroblasts (Glass et al., 1991; Palazzo et al., 2012). Significantly, despite this cyclic expression pattern, the amount of BDNF secreted by the nucleofected BDNFfibroblasts remained steady, if not slightly increasing in the later weeks of the study, suggesting that expression even longer than 6 months is likely.

\section{Nucleofected fibroblasts support the survival of spiral ganglion neurons in vitro}

Our co-culture experiments show that nucleofected fibroblasts secreting NT3 or BDNF elicit significant survival effects on SGN survival in vitro, in comparison to control EGFP-fibroblasts $(P<0.001)$.To thoroughly characterise the survival effects of the neurotrophin-expressing cells, we performed co-culture experiments utilising cells from two different time-points (8 and 16 weeks) post-transfection; however, we observed no significant difference in the survival effects for either population of cells. The amount of BDNF secreted by the BDNF-fibroblasts was not significantly different at these time-points; however, the amount of NT3 secreted by the NT3-fibroblasts was significantly greater at 8 weeks post-transfection $(\sim 300 \mathrm{pg} / \mathrm{mL})$ compared to at 16 weeks post-transfection $(\sim 10 \mathrm{pg} / \mathrm{mL})$. This suggests that there is likely a maximal neurotrophin concentration that will elicit survival effects on SGNs and amounts greater than this do not have an additional effect, as shown previously (Hory-Lee et al., 1993; Marzella et al., 1998). Furthermore, NT3-fibroblasts and BDNF-fibroblasts elicited similar survival effects on SGNs, although the amount of neurotrophin secreted from the NT3-fibroblasts was, on average, much greater than from the 
BDNF-fibroblasts (136.7 $\pm 17.2 \mathrm{pg} / \mathrm{mL}$ and $23.3 \pm 2.0 \mathrm{pg} / \mathrm{mL}$, respectively), suggesting that BDNF is more efficacious than NT3. Indeed, we have previously shown similar outcomes in this in vitro assay using Schwann cells lipofected to secrete BDNF or NT3 (Pettingill et al., 2008), in which the NT3-Schwann cells secreted significantly greater amount of neurotrophin than did the BDNF-Schwann cells and yet the survival effects were similar. This further supports the hypothesis that there is a maximal neurotrophin concentration for survival effects on SGNs, as described above. High concentrations of NT3 have also been shown to be toxic to SGNs in vitro (Marzella et al., 1998; Mamounas et al., 2000). Therefore, the concentration of NT3 present in this study may have had some toxicity on SGNs, preventing further survival effects. Nevertheless, the data presented here show that cell-based neurotrophin treatment can be used to support SGN survival in vitro.

Importantly, in vivo studies using pump systems or transfected cells to deliver neurotrophins have shown that both BDNF and NT3 are effective in supporting SGN survival and that the concentrations of neurotrophin secreted by nucleofected fibroblasts in this study are therapeutic in vivo (Miller et al., 1997; Gillespie et al., 2003; Gillespie et al., 2004; Pettingill et al., 2011). We have previously shown the potential for an encapsulated cell-based therapy over the short-term in vivo (Pettingill et al., 2011) and similar therapies are currently being assessed in advanced clinical trials as therapies for several degenerative diseases, including retinitis pigmentosa and age-related macular degeneration (Emerich and Thanos, 2008). The neurotrophin secreting fibroblasts developed in this study therefore represent a potential clinically relevant treatment to prevent SGN loss in deafness, if used in conjunction with encapsulation in a semi-permeable membrane to prevent immunorejection and cellular migration. 


\section{Conclusions}

We utilised different methods of gene transfer to genetically modify Schwann cells or fibroblasts to secrete BDNF or NT3. We established that fibroblasts that were nucleofected to express BDNF provided the greatest duration of neurotrophin secretion of at least 30 weeks, and that these BDNF-expressing fibroblasts were effective in supporting SGN survival in an in vitro model of deafness, which indicates that therapeutic levels of neurotrophins can be delivered using cell-based methods. Since a long-term means of inducing neuroprotective effects on SGNs is considered important for clinical translation, nucleofected fibroblasts show potential for further development in vivo. When combined with cell encapsulation, these cells could represent a clinically viable method for the delivery of BDNF to support SGN survival in the deafened cochlea. 


\section{Acknowledgements}

We thank Rebecca Argent for technical assistance, and Professor Johnson Mak for access to the AMAXA Nucleofector II. This work was supported by the National Health and Medical Research Council of Australia (APP526901) and the Garnett Passe and Rodney Williams Memorial Foundation. The Bionics Institute acknowledges the support it receives from the Victorian Government through its Operational Infrastructure Support Program. The funding bodies had no role in study design, data collection and analysis, decision to publish, or preparation of the manuscript.

\section{Author contributions}

MPZ, RKS and LNG designed the experiments; MH and ARH produced the lentiviral Schwann cells used for the experiments; MPZ and LNG performed the experiments and wrote the manuscript. All authors read and approved the final manuscript. 


\section{Table and Figure Legends}

Table 1. The effect of gene transfer method and cell type on neurotrophin expression.

Figure 1. Purity of fibroblast and Schwann cell cultures used for the transfections was determined via immunohistochemistry. The purity of the fibroblast cultures $(A$, phase contrast) was confirmed by positive immunostaining for Thy 1.1 (B) and negative staining for the S100 Schwann cell marker (C). Conversely, the purity of the Schwann cell cultures (D, phase contrast) was confirmed by negative staining for Thy1.1 (E) and positive immunostaining for $S 100(F)$. Secondary antibodies used were Alexa Fluor 488 (B, E) and Alexa Fluor 594 (C, F). Scale bars $=100 \mu \mathrm{m}$.

Figure 2. Neurotrophin expression from lipofected Schwann cells. Lipofected Schwann cells (LFSCs) were successfully genetically modified to express BDNF or NT3 and initially secreted significantly greater amounts of the respective neurotrophin than control EGFP-Schwann cells $(P<0.05)$,. Neurotrophin expression from these cells ceased by 6 and 10 weeks, respectively.

Figure 3. Neurotrophin expression from Schwann cells transduced with lentivirus. Schwann cells that were transformed using lentivirus (LVSCs) initially expressed significantly greater amounts of the respective neurotrophin than the control EGFPSchwann cells $(P<0.01)$, and showed expression of BDNF for nine weeks and NT3 for 14 weeks. 
Figure 4. Neurotrophin expression from lipofected fibroblasts. Lipofected fibroblasts (LFFbs) were successfully genetically modified to express BDNF or NT3 and secreted the respective neurotrophin at significantly greater levels than that of the associated control EGFP-fibroblasts $(P<0.01)$. Neurotrophin expression from these cells ceased by 9 and 11 weeks, respectively.

Figure 5. NT3 expression from nucleofected fibroblasts. Nucleofected NT3expressing fibroblasts (NFFbs) secreted significantly greater amounts of the neurotrophin than the control nucleofected EGFP-fibroblasts $(P<0.01)$, at an average of $136.7 \pm 17.2 \mathrm{pg} / \mathrm{mL} \mathrm{NT3}$, for 16 weeks.

Figure 6. BDNF expression from nucleofected fibroblasts. Nucleofected fibroblasts (NFFbs) were successfully genetically modified to express BDNF, with expression at levels significantly greater than controls $(P<0.01)$ observed over 30 weeks, at an average of $23.3 \pm 2.0 \mathrm{pg} / \mathrm{mL}$ BDNF.

Figure 7. SGN survival was enhanced following co-culture with neurotrophinexpressing cells. SGNs were co-cultured with fibroblasts that were nucleofected to express enhanced green fluorescent protein (EGFP-Fbs), neurotrophin-3 (NT3-Fbs) or brain-derived neurotrophic factor (BDNF-Fbs) for three days and were then stained and counted. Significant survival effects were observed on SGNs when cocultured with NT3-Fbs and BDNF-Fbs compared to EGFP-Fbs. Boxes depict the $25^{\text {th }}$ 
and $75^{\text {th }}$ percentiles bisected by the median, with whiskers illustrating the $5^{\text {th }}$ and $95^{\text {th }}$ percentiles; $\mathrm{n} \geq 37$; * $P<0.05$.

28. 


\section{References}

Agterberg MJ, Versnel H, van Dijk LM, de Groot JC and Klis SF (2009) Enhanced survival of spiral ganglion cells after cessation of treatment with brain-derived neurotrophic factor in deafened guinea pigs. J Assoc Res Otolaryngol 10:355367.

Badakov R and Jazwinska A (2006) Efficient transfection of primary zebrafish fibroblasts by nucleofection. Cytotechnology 51:105-110.

Brigadski T, Hartmann M and Lessmann V (2005) Differential vesicular targeting and time course of synaptic secretion of the mammalian neurotrophins. J Neurosci 25:7601-7614.

Brockes JP, Fields KL and Raff MC (1977) A surface antigenic marker for rat Schwann cells. Nature 266:364-366.

Emerich DF and Thanos CG (2008) NT-501: an ophthalmic implant of polymerencapsulated ciliary neurotrophic factor-producing cells. Curr Opin Mol Ther 10:506-515.

Ernfors P, Duan ML, EIShamy WM and Canlon B (1996) Protection of auditory neurons from aminoglycoside toxicity by neurotrophin-3. Nat Med 2:463-467.

Fritzsch B, Tessarollo L, Coppola E and Reichardt LF (2004) Neurotrophins in the ear: their roles in sensory neuron survival and fiber guidance. Prog Brain Res 146:265-278.

Gillespie LN, Clark GM, Bartlett PF and Marzella PL (2001) LIF is more potent than BDNF in promoting neurite outgrowth of mammalian auditory neurons in vitro. Neuroreport 12:275-279.

Gillespie LN, Clark GM, Bartlett PF and Marzella PL (2003) BDNF-induced survival of auditory neurons in vivo: Cessation of treatment leads to an accelerated loss of survival effects. J Neurosci Res 71:785-790.

Gillespie LN, Clark GM and Marzella PL (2004) Delayed neurotrophin treatment supports auditory neuron survival in deaf guinea pigs. Neuroreport 15:11211125.

Glass DJ, Nye SH, Hantzopoulos P, Macchi MJ, Squinto SP, Goldfarb M and Yancopoulos GD (1991) TrkB mediates BDNF/NT-3-dependent survival and proliferation in fibroblasts lacking the low affinity NGF receptor. Cell 66:405413.

Godinho MJ, Teh L, Pollett MA, Goodman D, Hodgetts SI, Sweetman I, Walters M, Verhaagen J, Plant GW and Harvey AR (2013) Immunohistochemical, ultrastructural and functional analysis of axonal regeneration through peripheral nerve grafts containing Schwann cells expressing BDNF, CNTF or NT3. PLoS One 8:e69987. 
Green SH, Bailey E, Wang Q and Davis RL (2012) The Trk A, B, C's of neurotrophins in the cochlea. Anat Rec (Hoboken) 295:1877-1895.

Haastert K, Mauritz C, Chaturvedi S and Grothe C (2007) Human and rat adult Schwann cell cultures: fast and efficient enrichment and highly effective nonviral transfection protocol. Nat Protoc 2:99-104.

Hamm A, Krott N, Breibach I, Blindt R and Bosserhoff AK (2002) Efficient transfection method for primary cells. Tissue Eng 8:235-245.

Hardie NA and Shepherd RK (1999) Sensorineural hearing loss during development: morphological and physiological response of the cochlea and auditory brainstem. Hear Res 128:147-165.

Hartmann M, Heumann R and Lessmann V (2001) Synaptic secretion of BDNF after high-frequency stimulation of glutamatergic synapses. EMBO J 20:5887-5897.

Haubensak W, Narz F, Heumann R and Lessmann V (1998) BDNF-GFP containing secretory granules are localized in the vicinity of synaptic junctions of cultured cortical neurons. J Cell Sci 111 ( Pt 11):1483-1493.

Hory-Lee F, Russell M, Lindsay RM and Frank E (1993) Neurotrophin 3 supports the survival of developing muscle sensory neurons in culture. Proc Natl Acad Sci U S A 90:2613-2617.

Hu Y, Arulpragasam A, Plant GW, Hendriks WT, Cui Q and Harvey AR (2007) The importance of transgene and cell type on the regeneration of adult retinal ganglion cell axons within reconstituted bridging grafts. Exp Neurol 207:314328.

Hu Y, Leaver SG, Plant GW, Hendriks WT, Niclou SP, Verhaagen J, Harvey AR and Cui Q (2005) Lentiviral-mediated transfer of CNTF to schwann cells within reconstructed peripheral nerve grafts enhances adult retinal ganglion cell survival and axonal regeneration. Mol Ther 11:906-915.

Kishino A, Katayama N, Ishige Y, Yamamoto Y, Ogo H, Tatsuno T, Mine T, Noguchi $\mathrm{H}$ and Nakayama C (2001) Analysis of effects and pharmacokinetics of subcutaneously administered BDNF. Neuroreport 12:1067-1072.

Lindholm D, Heumann R, Hengerer B and Thoenen H (1988) Interleukin 1 increases stability and transcription of mRNA encoding nerve growth factor in cultured rat fibroblasts. J Biol Chem 263:16348-16351.

Maisonpierre PC, Le Beau MM, Espinosa R, 3rd, Ip NY, Belluscio L, de la Monte SM, Squinto S, Furth ME and Yancopoulos GD (1991) Human and rat brainderived neurotrophic factor and neurotrophin-3: gene structures, distributions, and chromosomal localizations. Genomics 10:558-568.

Mamounas LA, Altar CA, Blue ME, Kaplan DR, Tessarollo L and Lyons WE (2000) BDNF promotes the regenerative sprouting, but not survival, of injured serotonergic axons in the adult rat brain. J Neurosci 20:771-782. 
Marzella PL, Clark GM, Shepherd RK, Bartlett PF and Kilpatrick TJ (1998) Synergy between TGF-beta 3 and NT-3 to promote the survival of spiral ganglia neurones in vitro. Neurosci Lett 240:77-80.

Matsuoka I, Meyer M and Thoenen H (1991) Cell-type-specific regulation of nerve growth factor (NGF) synthesis in non-neuronal cells: comparison of Schwann cells with other cell types. J Neurosci 11:3165-3177.

Maurisse R, De Semir D, Emamekhoo H, Bedayat B, Abdolmohammadi A, Parsi H and Gruenert DC (2010) Comparative transfection of DNA into primary and transformed mammalian cells from different lineages. BMC Biotechnol 10:9.

Miller JM, Chi DH, O'Keeffe LJ, Kruszka P, Raphael Y and Altschuler RA (1997) Neurotrophins can enhance spiral ganglion cell survival after inner hair cell loss. Int J Dev Neurosci 15:631-643.

Morrissey TK, Kleitman N and Bunge RP (1991) Isolation and functional characterization of Schwann cells derived from adult peripheral nerve. J Neurosci 11:2433-2442.

Nakayama A, Sato M, Shinohara M, Matsubara S, Yokomine T, Akasaka E, Yoshida $M$ and Takao S (2007) Efficient transfection of primarily cultured porcine embryonic fibroblasts using the Amaxa Nucleofection system. Cloning Stem Cells 9:523-534.

Palazzo E, Marconi A, Truzzi F, Dallaglio K, Petrachi T, Humbert P, Schnebert S, Perrier E, Dumas M and Pincelli C (2012) Role of neurotrophins on dermal fibroblast survival and differentiation. J Cell Physiol 227:1017-1025.

Pettingill LN, Minter RL and Shepherd RK (2008) Schwann cells genetically modified to express neurotrophins promote spiral ganglion neuron survival in vitro. Neuroscience 152:821-828.

Pettingill LN, Richardson RT, Wise AK, O'Leary SJ and Shepherd RK (2007) Neurotrophic factors and neural prostheses: potential clinical applications based upon findings in the auditory system. IEEE Trans Biomed Eng 54:11381148.

Pettingill LN, Wise AK, Geaney MS and Shepherd RK (2011) Enhanced auditory neuron survival following cell-based BDNF treatment in the deaf guinea pig. PLoS One 6:e18733.

Pfingst BE and Sutton D (1983) Relation of cochlear implant function to histopathology in monkeys. Ann N Y Acad Sci 405:224-239.

Plant GW, Currier PF, Cuervo EP, Bates ML, Pressman Y, Bunge MB and Wood PM (2002) Purified adult ensheathing glia fail to myelinate axons under culture conditions that enable Schwann cells to form myelin. J Neurosci 22:60836091. 
Poduslo JF and Curran GL (1996) Permeability at the blood-brain and blood-nerve barriers of the neurotrophic factors: NGF, CNTF, NT-3, BDNF. Brain Res Mol Brain Res 36:280-286.

Richardson RT, O'Leary S, Wise A, Hardman J and Clark G (2005) A single dose of neurotrophin-3 to the cochlea surrounds spiral ganglion neurons and provides trophic support. Hear Res 204:37-47.

Shepherd RK (2011) Rescuing the cochlea: the challenges. ENT \& audiology news 19:49-52.

Shepherd RK, Coco A and Epp SB (2008) Neurotrophins and electrical stimulation for protection and repair of spiral ganglion neurons following sensorineural hearing loss. Hear Res 242:100-109.

Shepherd RK, Coco A, Epp SB and Crook JM (2005) Chronic depolarisation enhances the trophic effects of BDNF in rescuing auditory neurons following a sensorineural hearing loss. J Comp Neurol 486:145-158.

Shepherd RK and Javel E (1997) Electrical stimulation of the auditory nerve. I. Correlation of physiological responses with cochlear status. Hear Res 108:112-144.

Skrzyszowska M, Samiec M, Slomski R, Lipinski D and Maly E (2008) Development of porcine transgenic nuclear-transferred embryos derived from fibroblast cells transfected by the novel technique of nucleofection or standard lipofection. Theriogenology 70:248-259.

Stankovic K, Rio C, Xia A, Sugawara M, Adams JC, Liberman MC and Corfas G (2004) Survival of adult spiral ganglion neurons requires erbB receptor signaling in the inner ear. J Neurosci 24:8651-8661.

Timm DE, de Haseth PL and Neet KE (1994) Comparative equilibrium denaturation studies of the neurotrophins: nerve growth factor, brain-derived neurotrophic factor, neurotrophin 3, and neurotrophin 4/5. Biochemistry 33:4667-4676.

Warnecke A, Sasse S, Wenzel Gl, Hoffmann A, Gross G, Paasche G, Scheper V, Reich U, Esser KH, Lenarz T, Stover T and Wissel K (2012) Stable release of BDNF from the fibroblast cell line NIH3T3 grown on silicone elastomers enhances survival of spiral ganglion cells in vitro and in vivo. Hear Res 289:86-97.

Warnecke A, Wissel K, Hoffmann A, Hofmann N, Berkingali N, Gro G, Lenarz T and Stover T (2007) The biological effects of cell-delivered brain-derived neurotrophic factor on cultured spiral ganglion cells. Neuroreport 18:16831686.

Wei BP, Robins-Browne RM, Shepherd RK, Clark GM and O'Leary SJ (2008) Can we prevent cochlear implant recipients from developing pneumococcal meningitis? Clin Infect Dis 46:e1-7. 
Winn SR, Lindner MD, Lee A, Haggett G, Francis JM and Emerich DF (1996) Polymer-encapsulated genetically modified cells continue to secrete human nerve growth factor for over one year in rat ventricles: behavioral and anatomical consequences. Exp Neurol 140:126-138.

Wise AK, Fallon JB, Neil AJ, Pettingill LN, Geaney MS, Skinner SJ and Shepherd RK (2011) Combining cell-based therapies and neural prostheses to promote neural survival. Neurotherapeutics 8:774-787.

Wise AK and Gillespie LN (2012) Drug delivery to the inner ear. J Neural Eng 9:065002.

Yamagata T, Miller JM, Ulfendahl M, Olivius NP, Altschuler RA, Pyykko I and Bredberg G (2004) Delayed neurotrophic treatment preserves nerve survival and electrophysiological responsiveness in neomycin-deafened guinea pigs. $J$ Neurosci Res 78:75-86.

Zanin MP, Pettingill LN, Harvey AR, Emerich DF, Thanos CG and Shepherd RK (2012) The development of encapsulated cell technologies as therapies for neurological and sensory diseases. J Control Release 160:3-13.

Zhang S, Zhou X and Rush R, 2001. Extraction and Quantification of the Neurotrophins. In: Rush, R. (Ed.), Methods in Molecular Biology, vol.169. Humana Press, Totowa, New Jersey, pp. 31-41.

Zilberstein Y, Liberman MC and Corfas G (2012) Inner hair cells are not required for survival of spiral ganglion neurons in the adult cochlea. J Neurosci 32:405410. 


\section{University Library}

\section{$\bullet-\underset{A C C E S S}{M} \operatorname{N} E R V A$}

\section{A gateway to Melbourne's research publications}

Minerva Access is the Institutional Repository of The University of Melbourne

Author/s:

Zanin, MP;Hellstroem, M;Shepherd, RK;Harvey, AR;Gillespie, LN

Title:

DEVELOPMENT OF A CELL-BASED TREATMENT FOR LONG-TERM NEUROTROPHIN EXPRESSION AND SPIRAL GANGLION NEURON SURVIVAL

\section{Date:}

2014-09-26

\section{Citation:}

Zanin, M. P., Hellstroem, M., Shepherd, R. K., Harvey, A. R. \& Gillespie, L. N. (2014).

DEVELOPMENT OF A CELL-BASED TREATMENT FOR LONG-TERM NEUROTROPHIN EXPRESSION AND SPIRAL GANGLION NEURON SURVIVAL. NEUROSCIENCE, 277, pp.690-699. https://doi.org/10.1016/j.neuroscience.2014.07.044.

Persistent Link:

http://hdl.handle.net/11343/43233 